\title{
A Highly Sensitive and Specific SARS-CoV-2 Spike- and Nucleoprotein-Based Fluorescent Multiplex Immunoassay (FMIA) to Measure IgG, IgA, and IgM Class Antibodies
}

\section{Solastie, Anna}

\section{$2021-12$}

Solastie , A , Virta , C , Haveri , A , Ekström , N , Kantele , A, Miettinen , S , Lempainen , J , Jalkanen , P , Kakkola , L , Dub , T , Julkunen , I \& Melin , M 2021 , ' A Highly Sensitive and Specific SARS-CoV-2 Spike- and Nucleoprotein-Based Fluorescent Multiplex Immunoassay (FMIA) to Measure IgG, IgA, and IgM Class Antibodies ' , Microbiology Spectrum , vol. 9 , no. 3 , e01131-21 . https://doi.org/10.1128/Spectrum.01131-21

http://hdl.handle.net/10138/340042

https://doi.org/10.1128/Spectrum.01131-21

cc_by

publishedVersion

Downloaded from Helda, University of Helsinki institutional repository.

This is an electronic reprint of the original article.

This reprint may differ from the original in pagination and typographic detail.

Please cite the original version. 


\title{
A Highly Sensitive and Specific SARS-CoV-2 Spike- and Nucleoprotein-Based Fluorescent Multiplex Immunoassay (FMIA) to Measure IgG, IgA, and IgM Class Antibodies
}

\author{
(D) Anna Solastie, ${ }^{a}$ Camilla Virta, ${ }^{a}$ Anu Haveri, ${ }^{a}$ Nina Ekström, ${ }^{a}$ Anu Kantele, ${ }^{b}$ Simo Miettinen, ${ }^{\mathrm{c}}$ Johanna Lempainen, ${ }^{\mathrm{d}, \mathrm{e}}$ Pinja Jalkanen, \\ Laura Kakkola, ${ }^{\mathrm{f}}$ Timothée Dub, ${ }^{\mathrm{g}}$ Ilkka Julkunen, ${ }^{\mathrm{f}, \mathrm{h}}$ Merit Melin ${ }^{\mathrm{a}}$ \\ aDepartment of Health Security, Expert Microbiology Unit, Finnish Institute for Health and Welfare, Helsinki, Finland \\ bMeilahti Infectious Diseases and Vaccination Research Center, MeiVac, Department of Infectious Diseases, Helsinki University Hospital and University of Helsinki, Helsinki, \\ Finland \\ cDepartment of Virology, University of Helsinki, Helsinki, Finland \\ dDepartment of Pediatrics, University of Turku and Turku University Hospital, Turku, Finland \\ eImmunogenetics Laboratory, Institute of Biomedicine, University of Turku, Turku, Finland \\ IInfection and Immunity, Institute of Biomedicine, University of Turku, Turku, Finland \\ gDepartment of Health Security, Infectious Disease Control and Vaccinations Unit, Finnish Institute for Health and Welfare, Helsinki, Finland

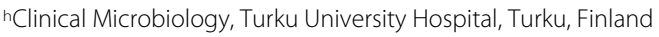

ABSTRACT Validation and standardization of accurate serological assays are crucial for the surveillance of the coronavirus disease 2019 (COVID-19) pandemic and population immunity. We describe the analytical and clinical performance of an in-house fluorescent multiplex immunoassay (FMIA) for simultaneous quantification of antibodies against the severe acute respiratory syndrome coronavirus 2 (SARS-CoV-2) nucleoprotein and spike glycoprotein. Furthermore, we calibrated IgG-FMIA against World Health Organization (WHO) International Standard and compared FMIA results to an in-house enzyme immunoassay (EIA) and a microneutralization test (MNT). We also compared the MNT results of two laboratories. IgG-FMIA displayed $100 \%$ specificity and sensitivity for samples collected 13 to 150 days post-onset of symptoms (DPO). For IgA- and IgM-FMIA, 100\% specificity and sensitivity were obtained for a shorter time window (13 to 36 and 13 to 28 DPO for IgA- and IgM-FMIA, respectively). FMIA and EIA results displayed moderate to strong correlation, but FMIA was overall more specific and sensitive. IgG-FMIA identified $100 \%$ of samples with neutralizing antibodies (NAbs). Anti-spike lgG concentrations correlated strongly ( $\rho=0.77$ to $0.84, P<2.2 \times 10^{-16}$ ) with NAb titers, and the two laboratories' NAb titers displayed a very strong correlation $\left(\rho=0.95, P<2.2 \times 10^{-16}\right)$. Our results indicate good correlation and concordance of antibody concentrations measured with different types of in-house SARS-CoV-2 antibody assays. Calibration against the WHO international standard did not, however, improve the comparability of FMIA and EIA results.

IMPORTANCE SARS-CoV-2 serological assays with excellent clinical performance are essential for reliable estimation of the persistence of immunity after infection or vaccination. In this paper we present a thoroughly validated SARS-CoV-2 serological assay with excellent clinical performance and good comparability to neutralizing antibody titers. Neutralization tests are still considered the gold standard for SARSCoV-2 serological assays, but our assay can identify samples with neutralizing antibodies with $100 \%$ sensitivity and $96 \%$ specificity without the need for laborious and slow biosafety level 3 (BSL-3) facility-requiring analyses.

KEYWORDS SARS-CoV-2, COVID-19, antibody, immunoassay, nucleoprotein, spike glycoprotein, WHO international standard, neutralizing antibodies, microneutralization, receptor-binding domain
Editor Rosemary C. She, Keck School of Medicine of the University of Southern California

Copyright $\odot 2021$ Solastie et al. This is an open-access article distributed under the terms of the Creative Commons Attribution 4.0 International license. Address correspondence to Anna Solastie, anna.solastie@thl.fi.

Received 4 August 2021

Accepted 25 October 2021

Published 17 November 2021 
evere acute respiratory syndrome coronavirus 2 (SARS-CoV-2), the causative agent of coronavirus disease 2019 (COVID-19), had claimed over 4 million lives and infected 190 million people by August 2021 (1). A large proportion of all infections may go undetected in their acute phase $(2,3)$ for various reasons, such as lack of symptoms $(4,5)$ or hesitancy of getting tested (6). Therefore, accurate serological assays are needed to provide more reliable estimates of COVID-19 prevalence.

SARS-CoV-2 serological assays are useful anywhere between determining seroprevalence in the general population to the investigation of confined outbreaks. In neutralization tests and other serological tests alike, the clinical specificity and sensitivity of the assays can vary considerably (7-12). Comparisons of methods and their standardization is urgently needed to properly understand and apply vast acquired information on the immunity induced by SARS-CoV-2 infection and COVID-19 vaccines.

We describe the validation and performance of an in-house fluorescent multiplex immunoassay (FMIA) developed for quantification of antibodies produced against three SARSCoV-2 antigens-the full-length spike glycoprotein (SFL), spike receptor-binding domain (RBD), and nucleoprotein (N). Our assay detects antibodies against these three antigens simultaneously, which enables differentiation of natural SARS-CoV-2 infection from vaccineinduced immunity. The assay is based on an FMIA previously described by Trivedi et al. (13) We have recently reported the performance of the FMIA for measuring IgG antibodies against SARS-CoV-2 nucleoprotein (14). Here, we report our findings on the analytical and clinical performance of FMIA and compare its $\lg G$, IgA, and IgM assay results to another laboratory's in-house enzyme immunoassay (EIA) $(15,16)$, both calibrated for IgG with the WHO international standard (17). Furthermore, we compare FMIA antibody levels to neutralizing antibody (NAb) titers $(14,18)$ and NAb titers of microneutralization tests (MNTs) between two separate laboratories.

\section{RESULTS}

Analytical performance of the FMIA. We calculated the limit of quantification (LOQ) and limit of detection (LOD) separately for each antigen and each antibody class, and the data are presented in Table S2 in the supplemental material. For IgA and IgM assays, the linearity with different serum dilutions was excellent for all antigens (range, $R^{2}=0.96$ to 1 ). For the IgG assay, less diluted samples (dilutions of 1:100 and 1:200) resulted in relatively lower lgG concentrations leading to weaker linearity correlations. Exclusion of dilutions of 1:100 and 1:200 resulted in an $R^{2}$ of $\geq 0.99$ for all antigens in the lgG assay. As a compromise to avoid decreased clinical sensitivity and to minimize the number of serum dilutions, we decided to calculate antibody concentrations from the average of 1:100 and 1:1,600 dilutions for all except negative sample panels sera, which were analyzed at a dilution of 1:100.

The mean intra-assay variation ranged from 8 to $10 \%$, and the interassay variation ranged from 4 to $12 \%$ in the different antibody classes (Table S3). The mean variation between technicians was $20 \%$ for $\lg$, $21 \%$ for $\operatorname{lgA}$ and $18 \%$ for IgM assays. The variation between four batches of conjugated microspheres was $16 \%$, and the variation between batches of detection antibodies was $15 \%$ for lgA and lgG assays. Overall, both intra- and interassay variation were found acceptable for all antibody classes and antigens.

Calibration against WHO international standard. The lgG-specific concentrations against $\mathrm{N}, \mathrm{RBD}$, and SFL of the in-house reference serum calibrated against the WHO international standard (17) were 34, 18, and 23 binding antibody units $(B A U) / \mathrm{mL}$, respectively. Because the starting dilution of IgG-specific in-house reference sera was given an arbitrary concentration of $100 \mathrm{FMIA} \mathrm{U/mL}$, we multiplied the results by a factor of 0.34 for nucleoprotein, 0.18 for RBD, and 0.23 for SFL to obtain calibrated BAU/ $\mathrm{mL}$. In the EIA, the calibration factor for $\mathrm{N} \lg G$ was 12.9; for $\mathrm{N}$ total $\mathrm{lg}, 17.4$; for S1 IgG, 11.8; and for S1 total Ig assay, 12.0. We did not calibrate MNTs but obtained a titer of 192 against FIN-1 virus in laboratory 1 and 640 against FIN-25 in laboratory 2 for the WHO international standard.

Clinical performance of the FMIA. We set the thresholds for positivity based on a positive panel of convalescent-phase sera $(n=147)$ and a negative-serum panel 
TABLE 1 Thresholds, clinical specificity, and clinical sensitivity of FMIA measuring SARS-CoV-2 antibodies from convalescent-phase sera ${ }^{a}$

\begin{tabular}{|c|c|c|c|c|c|}
\hline Antibody & $\begin{array}{l}\text { FMIA threshold } \\
(\mathrm{U} / \mathrm{mL})\end{array}$ & $\begin{array}{l}\text { WHO standard adjusted threshold } \\
\text { (BAU/mL) }\end{array}$ & $\begin{array}{l}\text { DPO of optimal } \\
\text { sensitivity }\end{array}$ & $\begin{array}{l}\text { Specificity (\%) } \\
\left(95 \% \mathrm{Cl}^{b}\right)\left(n^{c}\right)\end{array}$ & $\begin{array}{l}\text { Sensitivity (\%) } \\
\left(95 \% \mathrm{Cl}^{b}\right)\left(n^{d}\right)\end{array}$ \\
\hline$\overline{\lg G}$ & $\mathrm{SFL} \geq 0.388$ and $\mathrm{RBD} \geq 0.712$ & $\mathrm{SFL} \geq 0.089$ and $\mathrm{RBD} \geq 0.13$ & $13-150$ & $100(99.1-100)(402)$ & $100(97.3-100)(140)$ \\
\hline $\lg A$ & $\mathrm{SFL} \geq 3.88$ and $\mathrm{RBD} \geq 11.4$ & & $13-36$ & $100(99.1-100)(402)$ & $100(94.7-100)(69)$ \\
\hline
\end{tabular}

${ }^{a} \mathrm{RBD}$, receptor binding domain of SARS-CoV-2 (Wuhan-Hu-1) spike glycoprotein; SFL, full-length spike glycoprotein of SARS-CoV-2 (Wuhan-Hu-1); DPO, days post-onset of symptoms.

bWilson confidence interval.

'Number of negative samples used for calculations.

${ }^{d}$ Number of positive samples used for calculations, which includes only part of the positive serum panel and differs between antibody classes due to exclusion of samples that did not meet DPO of optimal sensitivity criteria.

( $n=402$ ), aiming to achieve $100 \%$ specificity. We considered a sample positive for antispike IgG antibodies (S-lgG) if it had $\geq 0.13$ and $\geq 0.089 \mathrm{BAU} / \mathrm{mL}$ anti-RBD and anti-SFL IgG antibodies, respectively. With these thresholds, the specificity of the S-IgG FMIA was $100 \%$ (95\% confidence interval $[\mathrm{Cl}], 99.1$ to 100 ) (Table 1). The sensitivity of the FMIA for detecting antibodies in convalescent-phase sera was dependent on days post-onset of symptoms (DPO) (Table 1). The sensitivity of the S-IgG FMIA assessed based on the positive-serum panel (DPO 4 to $150, n=147$ ) was $97 \%(95 \% \mathrm{Cl}, 93.2$ to 98.9). All samples with IgG concentrations under the thresholds $(n=7 / 147)$ were collected 4 to 11 DPO (Fig. 1). The sensitivity of the S-IgG FMIA was 100\% $(95 \% \mathrm{Cl}, 97.3$ to 100) for samples collected 13 to 150 DPO $(n=140)$ (Table 1). With the positive-serum panel used in this study $(n=147)$, the specificity and sensitivity of the N-IgG FMIA we have previously described (14) were 100\% for samples collected 21 to 51 DPO, but the sensitivity of the assay decreased to $98 \%$ for samples collected 52 to 150 DPO (Fig. 2).

The optimal threshold for IgA-FMIA was also based on the simultaneous detection of both spike antibodies. We considered a sample positive for IgA antibodies if it contained $\geq 11.4$ and $\geq 3.88 \mathrm{FMIA} \mathrm{U/ml} \mathrm{anti-RBD}$ and anti-SFL IgA antibodies, respectively, which resulted in $100 \%$ specificity $(95 \% \mathrm{Cl}, 99.1$ to 100$)$ (Table 1). For samples collected 13 to 36 DPO ( $n=69)$, the sensitivity was $100 \%(95 \% \mathrm{Cl}, 94.7$ to 100$)$. As DPO increased, sensitivity decreased as a lower number of the positive serum panel's samples reached the thresholds (Fig. 2).

The optimal threshold for IgM-FMIA was based only on the concentration of antiSFL antibodies, as the addition of RBD or N to the threshold criteria did not result in higher specificity or sensitivity. We considered samples that contained $\geq 17.5$ FMIA U/ $\mathrm{mL}$ anti-SFL IgM antibodies positive for IgM. The specificity of the IgM assay was $100 \%$ $(95 \% \mathrm{Cl}, 99.1$ to 100$)$ with this threshold (Table 1). DPO range resulting in 100\% sensitivity was 13 to 28 days for IgM ( $95 \% \mathrm{Cl}$ for sensitivity, 91.0 to $100 ; n=39$ ) (Table 1). As DPO increased, the sensitivity of the IgM assay decreased steeply (Fig. 2).

Comparison of FMIA and MNT. NAb titers exhibited a strong ( $\rho=0.77$ to 0.84$)$ and statistically significant correlation $\left(P<2.2 \times 10^{-16}\right)$ with S-IgG concentrations (Fig. 3). All samples that contained NAb were also positive in IgG-FMIA regardless of DPO (Table S4). Therefore, the S-IgG FMIA was $100 \%$ (95\% Cl, 97.3 to 100) sensitive and $96 \%$ $(95 \% \mathrm{Cl}, 91.1$ to 98.4$)$ specific for identification of NAb from samples taken 4 to 150 DPO. Some samples were negative in MNT but positive for S-IgG in FMIA (Table S4), indicating that not all antibodies that bind to SFL and RBD antigens used in FMIA are neutralizing. The ability of IgA- and IgM-FMIA to identify samples positive for NAbs was dependent on DPO in a manner similar to their clinical sensitivity, indicating the different kinetics of IgA and IgM compared to NAb antibodies (Table S4, Fig. 2).

Comparison of FMIA and EIA. We compared the results of FMIA and EIA by analyzing a panel of convalescent-phase serum samples $(n=20)$ and pre- and postvaccination samples $(n=60)$ of 20 subjects. We observed the strongest correlations ( $\rho=0.94$ to 0.95 ) between FMIA and EIA for IgG (FMIA) and IgG or total Ig (EIA) antibody concentrations against SARS-CoV-2 spike antigens (Fig. 4). FMIA and EIA anti-spike antibody concentrations also displayed a strong correlation in IgA and IgM assays ( $\rho=0.79$ for $\lg A, \rho=0.88$ for $\lg M$; Fig. S2). The correlation between anti-N concentrations of $\lg G$ 


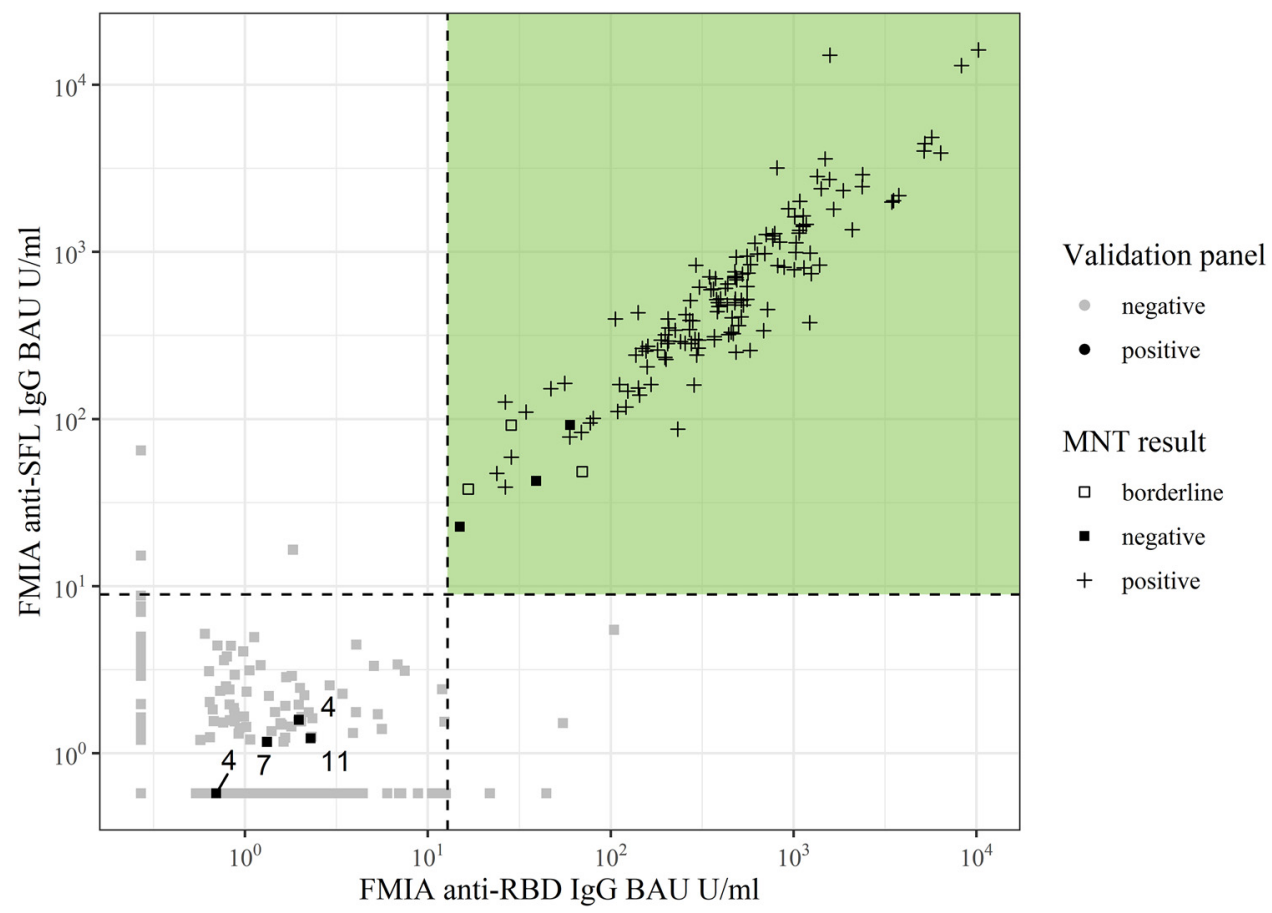

FIG 1 Anti-SFL and -RBD lgG antibody concentrations (BAU/mL) of positive-serum (black, $n=147$ ) and negativeserum (gray, $n=402$ ) panels measured with FMIA. Dashed lines represent IgG SFL and RBD assay thresholds, and samples that pass both thresholds (colored area) are classified as positive for SARS-CoV-2 spike-specific IgG antibodies. The numbers indicate days post-onset of symptoms for samples that belong to the positive-serum panel but were categorized as negative for anti-spike lgG antibodies in FMIA. MNT result, microneutralization test interpretation; $<4$, negative; 4, borderline; $>4$, positive; RBD, receptor binding domain of SARS-CoV-2 (Wuhan-Hu-1) spike glycoprotein; SFL, full-length spike glycoprotein of SARS-CoV-2 (Wuhan-Hu-1).

FMIA and EIA was moderate ( $\rho=0.54$; Fig. 4). Thus, FMIA and EIA differed to some extent in their ability to measure antibodies induced by SARS-CoV-2 infection and COVID-19 mRNA vaccination.

Of convalescent patient sera (14 to 60 DPO), 20/20 had anti-N and -S-IgG antibodies in FMIA, while 15/20 had anti-N and 11/20 had anti-S1 in IgG EIA and 19/20 had anti-N and $17 / 20$ had anti-S1 antibodies in ElA total Ig assay. Anti-spike IgA antibodies were identified in $18 / 20$ of patients when measured with FMIA, but only $1 / 20$ had anti-S1 IgA antibodies with EIA. Anti-spike IgM antibodies were identified in 18/20 and 20/20 of patients with FMIA and EIA, respectively. Of the samples collected before vaccination, 1/20 (IgG FMIA), 0/20 (IgG EIA), and 5/20 (EIA total Ig) had anti-N antibodies while lacking anti-spike antibodies. Of samples collected at 3 weeks after vaccination, 20/20 were positive for anti-spike IgG in FMIA and 18/20 in EIA; 20/20 samples were positive at 6 weeks with both assays.

When we compared the IgG concentrations in convalescent and postvaccination samples measured with FMIA and EIA, the mean coefficient of variation (CV) between FMIA U/mL and EIA units was $80 \%$. The mean CV increased to $130 \%$ when results were converted to BAU/mL. Hence, calibration with the WHO standard did not increase the comparability of FMIA and EIA but increased the variation between the two assays instead.

Comparison of MNTs. We compared the results of the NAb titers of two laboratories with the same convalescent, pre-, and postvaccination serum panels as with FMIA and EIA. The correlation between NAb titers of the two laboratories was very strong at $\rho=0.95\left(P<2.2 \times 10^{-16}\right)$ (Fig. 5). Both MNTs classified $20 / 20$ day 0 samples as negative and 20/20 6-week postvaccination samples as positive. The MNT of laboratory 1 was more sensitive at 3 weeks by identifying $18 / 20$ of samples as having NAbs 


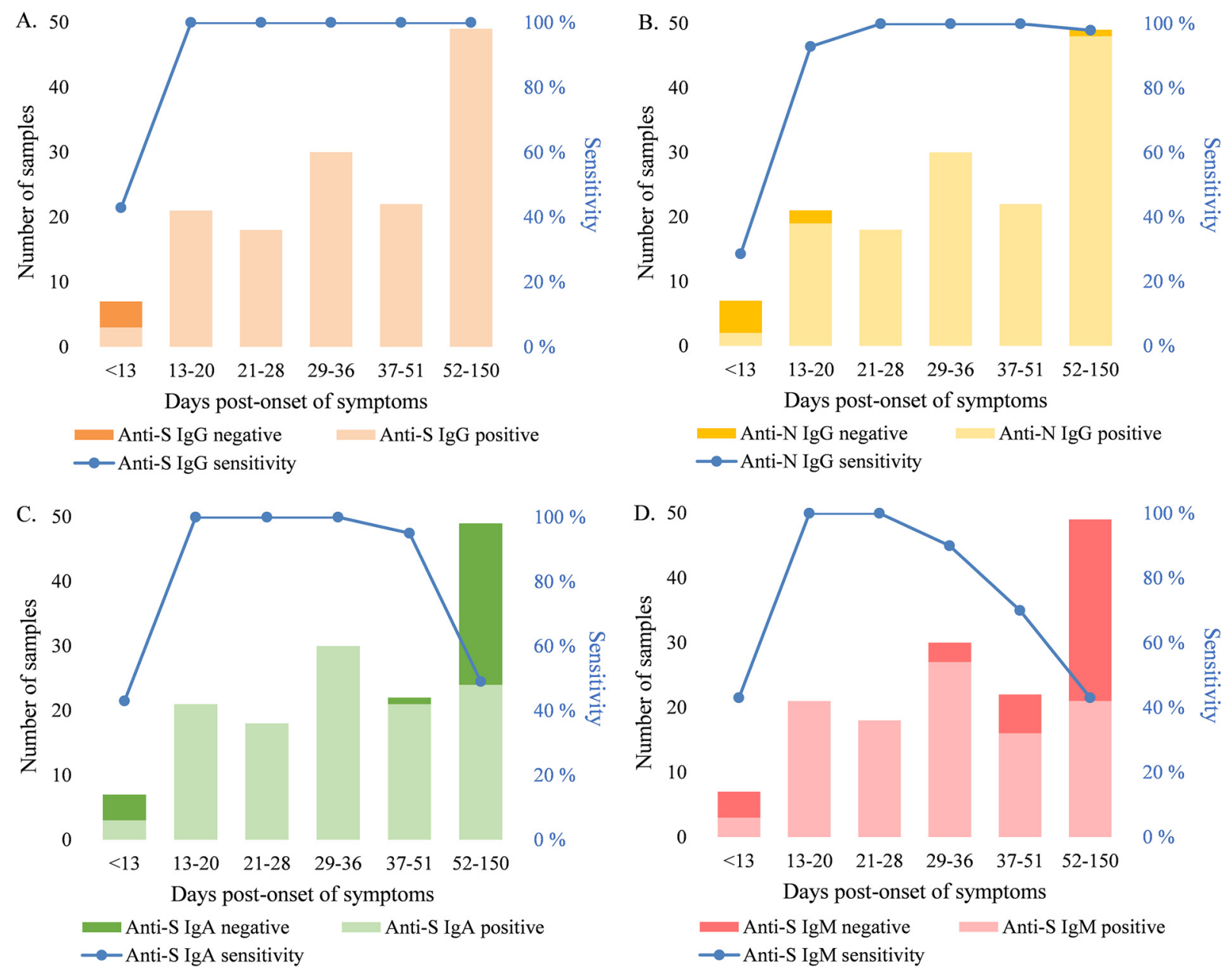

FIG 2 Sensitivity (\%) of SARS-CoV-2 FMIA and the effect of time post-onset of symptoms (DPO). (A) Anti-S (SFL and RBD) IgG FMIA. (B) Anti$\mathrm{N}$ IgG FMIA. (C) Anti-S (SFL and RBD) IgA FMIA. (D) Anti-S (SFL) IgM FMIA. RBD, receptor binding domain of SARS-CoV-2 (Wuhan-Hu-1) spike glycoprotein; SFL, full-length spike glycoprotein of SARS-CoV-2 (Wuhan-Hu-1); N, SARS-CoV-2 nucleoprotein of SARS-CoV-2 (Wuhan-Hu-1).

compared to $12 / 20$ from laboratory 2 . Among convalescent-phase patient sera, NAbs were found in 19/20 of samples in laboratory 1 and 18/20 of samples in laboratory 2.

\section{DISCUSSION}

We evaluated the analytical and clinical performance of SARS-CoV-2 FMIA and compared FMIA to other serological assays. The clinical performance of the FMIA was excellent, reaching $100 \%$ sensitivity and specificity. The clinical performance of S-IgG FMIA did not decrease through the sample collection period (150 days, or 5 months). The sensitivity of IgA- and IgM-FMIA decreased with increasing DPOs, consistent with the shorter half-lives of $\lg A$ and $\lg M$ antibodies (19).

FMIA performed well in comparison to the in-house EIA antibody test. The correlation between FMIA and EIA IgG and total Ig results was strong for spike glycoprotein and moderate for nucleoprotein. Our results indicate that both methods accurately recognize vaccine-induced antibody responses at 6 weeks but that FMIA is slightly more sensitive than EIA in samples taken 3 weeks after the 1 st vaccine dose. As we compared the MNTs of two laboratories, we found that NAb titers had a very strong correlation despite some differences in the methodology. Overall, the MNT of one of the laboratories was somewhat more sensitive, which is likely explained by less diluted sera and different viral strains (lineage B versus B.1).

The limitations of this study are related to the sample material used in the validation process of FMIA. In essence, the thresholds and DPOs described here were 

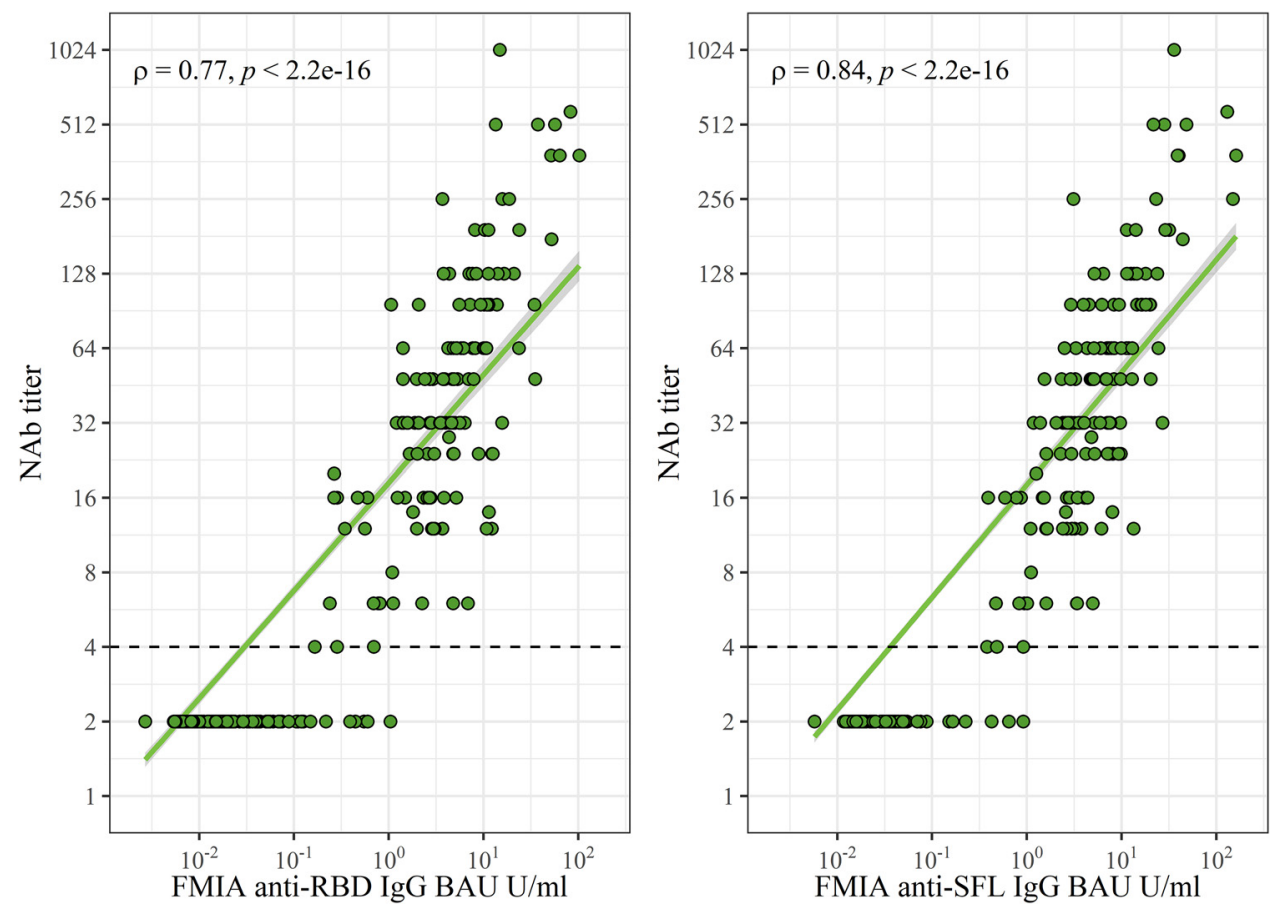

FIG 3 Spearman correlation $(\rho)$ and significance $(P)$ between FMIA anti-spike antibody concentrations and neutralizing antibody (NAb) titers. The dashed line marks the threshold for positive MNT results ( $>4$ ). One point may represent multiple samples $(n=549)$. RBD, receptor binding domain of SARS-CoV-2 (Wuhan-Hu- 1 ) spike glycoprotein. SFL, full-length spike glycoprotein of SARS-CoV-2 (Wuhan-Hu-1).

optimized for the detection of previous infections with mild to moderate symptoms. Despite this, the S-IgG levels correlated strongly with NAb titers. Our results also suggest that FMIA is better at recognizing samples with NAbs than many commercial assays (12). While S-IgG FMIA identified all samples with NAbs, it does not necessarily measure antibodies against neutralizing epitopes only, as some samples negative in MNT were considered positive for S-IgG. We conclude that FMIA is valuable in prescreening of serum samples prior to confirmatory MNT. As the anti-SARS-CoV-2 antibody levels have been found to correlate with the disease severity (20-22), we can expect FMIA to perform well also in the serological diagnostics of previous severe infections. Importantly, while the present data show an excellent sensitivity for IgG-FMIA until 150 DPO, its performance after that remains to be investigated.

Estimates of the persistence of immunity to COVID-19 appear to depend on the serological assay used $(11,23)$. We recently reported that 6 and 12 months after SARSCoV-2 infection $98 \%$ and $97 \%$ of the patients, respectively, still had S-IgG in FMIA (24). Other recent studies have found that anti-spike IgG antibodies persist in $90 \%$ of individuals 7 (25) and 9 months (26) after a confirmed SARS-CoV-2 infection. We found no decrease in the sensitivity of the spike-based IgG-FMIA in samples collected up to 5 months after infection. Anti-nucleoprotein antibodies have been reported to wane faster $(24,27)$, consistent with our findings of sensitivity decreasing from $100 \%$ to $98 \%$ for N-IgG FMIA 52 to 150 DPO. Together with data of persisting antibodies, our findings imply that S-IgG FMIA continues to be reliable in the detection of antibodies produced against SARS-CoV-2 for at least several months after infection.

Notably, the participants providing convalescent-phase serum samples for the positive-serum panel were likely all infected with a B.1 lineage virus since the samples were collected in Finland from March to September 2020. However, by using two spike antigens (RBD and SFL), both of which include multiple antibody binding sites, FMIA is less likely to lose performance when facing infections caused by various SARS-CoV-2 variants. The combination of antigens makes FMIA also less susceptible to possible cross-reactivity 

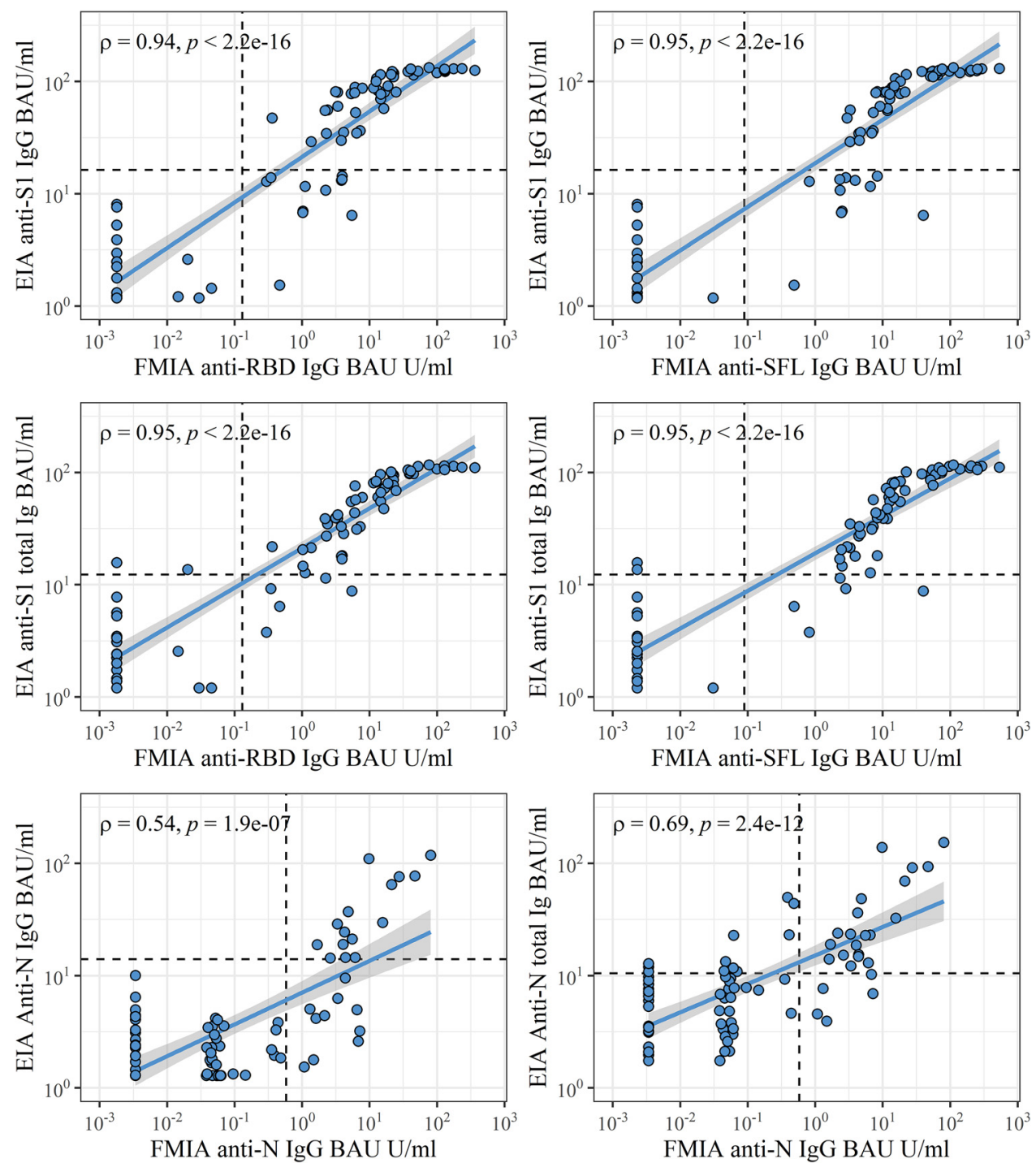

FIG 4 Spearman correlation $(\rho)$ and significance $(p)$ between FMIA IgG and EIA IgG and total anti-spike Ig antibodies in binding antibody units $(\mathrm{BAU} / \mathrm{mL})$ calibrated against the WHO international standard. Dashed lines mark thresholds for positivity per antigen. One point may represent multiple samples $(n=80)$. S1, SARS-CoV-2 spike glycoprotein S1 subunit; RBD, receptor binding domain of SARS-CoV-2 (Wuhan-Hu-1) spike glycoprotein; SFL, full-length spike glycoprotein of SARS-CoV-2 (Wuhan-Hu-1); N, SARS-CoV-2 nucleoprotein of SARS-CoV-2 (Wuhan-Hu-1).

with antibodies produced against seasonal coronaviruses. Additionally, FMIA could be used to distinguish immune response induced by COVID-19 vaccination and recent SARS-CoV-2 infection.

The need for highly sensitive and specific antibody tests will continue in the future as new variants emerge fueling further COVID-19 waves. Here, we have described a reliable antibody assay for the simultaneous quantification of multiple SARS-CoV-2 antibodies, with excellent clinical performance and good comparability with NAb titers. We have also described the calibration of FMIA against a WHO international standard, which has been reported to reduce interlaboratory variation (28). However, we observed that calibrating FMIA and EIA only emphasized the differences between their results. In FMIA the results are calculated from a standard curve, and in EIA the results are calculated from the ratio between a sample and two controls. Although standardization of SARS-CoV-2 antibody assays is urgently needed, our results indicate only a limited value for the international standard in calibrating two assays whose test 


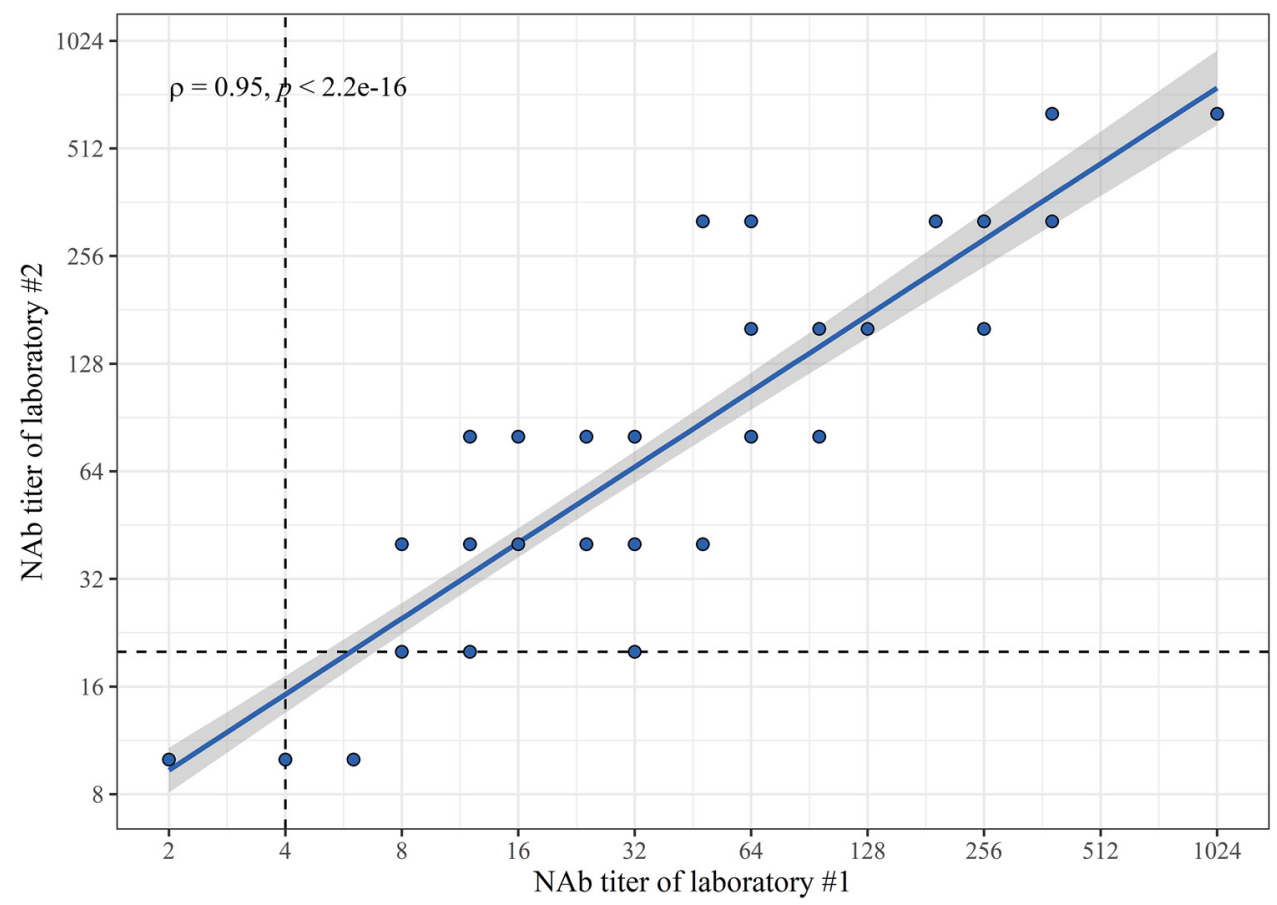

FIG 5 Spearman correlation $(\rho)$ and significance $(p)$ between neutralizing antibody (NAb) titers of two laboratories. Dashed lines mark thresholds for positivity ( $\geq 4$ for laboratory 1 and $\geq 20$ for laboratory 2 ). One point may represent multiple samples $(n=80)$.

principles are quite different. The applicability and value brought by calibration should be considered when used in comparisons between methodologically diverse assays.

\section{MATERIALS AND METHODS}

Serum samples. We assessed the analytical and clinical performance of the FMIA by using negativeand positive-sample panels. The negative-sample panel consisted of 402 anonymous serum samples collected in mid-2019 before the COVID-19 pandemic. The positive-serum panel consisted of 147 samples collected from 58 volunteers as part of a COVID-19 household transmission study (29). These samples were collected 4 to 150 days post-onset of symptoms (DPO) and 0 to 147 days post-positive PCR test result for SARS-CoV-2. Thus, the negative- and positive-serum panels consisted of a total of 549 samples. Details of the panels are presented in Table S1 and Fig. S1.

We compared FMIA with EIA using a serum panel that consisted of a subset of 80 samples collected as part of a COVID-19 mRNA vaccine response study (16). We collected 1 sample from 20 convalescentphase PCR-confirmed COVID-19 outpatients and 3 samples from 20 volunteer health care workers $(n=60)$ who received two doses of the Pfizer-BioNTech BNT162b2 mRNA vaccine. We collected sera from the convalescent-phase patients 15 to 41 (median 26) DPO. We collected sera from vaccinated volunteers before or on the day of the vaccination (day 0 samples), 3 weeks (median 21 days, range 18 to 21) post 1 st vaccine dose (3-week samples), and 6 weeks (median 48 days, range 39 to 50 ) post 1 st vaccine dose (6-week samples). At the time of the 6-week sample collection, 3 weeks (median 27 days, range 18 to 29 ) had also passed from the 2 nd vaccine dose. Participant demographics are presented in Table S1.

The SARS-CoV-2 FMIA. Here, we adapted the previously described SARS-CoV-2 FMIA (14) for the measurement of IgG, IgA, and IgM antibodies against SARS-CoV-2 RBD, SFL, and N antigens. Briefly, we conjugated SARS-CoV-2 RBD (product codes REC31849), SFL (REC31868), and N (REC31812; Native Antigen Company, Oxford, United Kingdom) antigens on the surfaces of MagPlex-C superparamagnetic carboxylated microspheres (Luminex, Austin, TX, USA) by carbodiimide reaction. We added the microspheres onto black 96-well plates (Costar 3915; Corning, Kennebunk, ME, USA) with diluted sera and reference and control samples and incubated it at room temperature with shaking at $600 \mathrm{rpm}$ in the dark for $1 \mathrm{~h}$. We washed the unbound particles away with a magnetic plate washer (ELx405 and 405TSRS; BioTek, Winooski, VT, USA) and added R-phycoerythrin-conjugated AffiniPure goat anti-human IgG, IgA, or $\operatorname{lgM} \mathrm{Fc} \gamma$ fragment-specific detection antibodies (Jackson ImmunoResearch, Cambridge, United Kingdom) to the wells. We incubated the plates for $30 \mathrm{~min}$ as described above and then washed them again. We measured the median fluorescence intensity (MFI) with the MAGPIX system (Luminex). MFI values were automatically converted into antibody concentration (FMIA U/mL) via interpolation from 5parameter logistic (5-PL) curves (xPONENT software version 4.2; Luminex) created from serially diluted (1:400 to $1: 1,638,400)$ in-house reference serum. We gave the $1: 400$ dilution of the standard an arbitrary 
concentration of 100 FMIA U/mL. We performed the FMIA analyses at the Finnish Institute for Health and Welfare (Helsinki, Finland). A full description of the FMIA method is presented in the supplemental material.

Limit of detection (LOD) and limit of quantification (LOQ). We determined LOD and LOQ from 26 experiments by calculating the mean $+3 \times(\mathrm{LOD})$ and $8 \times(\mathrm{LOQ})$ standard deviation of MFI values generated from blank wells $(n=52)$. MFI values were converted into FMIA U/mL by interpolation from the 5-PL reference curve with GraphPad Prism version 9.

Linearity. We assessed the linearity of FMIA by comparing the antibody concentration of serially diluted $(1: 100,1: 200,1: 400,1: 800$, and 1:1,600) sera (lgG, $n=6 ; \lg A$ and $\lg M, n=7)$ collected as part of the COVID-19 household transmission study (29). Linearity was measured as the Pearson correlation between dilution factor and antibody concentration, and a mean $R^{2}$ of $\geq 0,95$ of all samples was considered acceptable.

Precision and reproducibility. We assessed the precision and reproducibility of FMIA as the mean percentage of the coefficient of variation (CV\%) of antibody concentrations between samples analyzed repeatedly in different settings. Precision was assessed as intra- and interassay variation and reproducibility by comparing the results obtained by three laboratory technicians and as variation caused by different batches of crucial reagents. A full description of the evaluation of analytical performance is presented in the supplemental material.

Evaluation of the clinical performance of FMIA. We determined the clinical performance of the antibody assays as their ability to distinguish negative-panel (pre-COVID19 era) and positive-panel (PCRconfirmed patients) sera. We determined the thresholds for positivity by comparing all possible threshold combinations for the three antigens with $\mathrm{R}$ (version 3.6.0) and RStudio (version 1.2.1335). We prioritized a specificity of $100 \%$ and determined it with the entire negative serum panel $(n=402)$. Sensitivity was assessed separately for subgroups of the positive serum panel's samples $(n=147)$ based on DPOs.

EIA. The SARS-CoV-2 EIA used in this study has previously been described in detail (15). We measured IgG, IgA, IgM, and total Ig antibodies against SARS-CoV-2 S1 and N proteins from sera diluted 1:300. SARS-CoV-2 S1 (GenBank accession number MN908947.3) and N (GenBank accession no. NC_045512.2) antigens were expressed and purified, and antigen-specific antibody levels were measured with a VICTOR Nivo device (PerkinElmer, Turku, Finland) as described previously (16). We converted the results into EIA units by comparing the absorbance values of samples with the absorbance values of 1:300-diluted positive controls (marked as 100 EIA units) and 1:300-diluted negative controls (marked as 0 EIA units) included in each assay. Thresholds for positivity were previously determined with 20 negative serum samples (16). We performed the EIA analyses at the University of Turku (Turku, Finland).

Calibration against the WHO international standard. We calibrated the FMIA's IgG-specific inhouse reference serum against a WHO international standard (NIBSC, code 20/136 [17]; Hertfordshire, United Kingdom). We serially diluted the in-house reference serum and WHO international standard and assigned the 1:100 dilution of the WHO international standard a concentration of 10 binding antibody units $(\mathrm{BAU}) / \mathrm{mL}$. We conducted the analysis on two separate days and interpolated the mean concentration for each dilution of the in-house reference serum from the linear range of the WHO international standard. With EIA, we used the WHO international standard to calibrate the positive control by diluting both at 1:300 and calculating their ratio. We performed the EIA analysis once and used the average absorbance values calculated from duplicate wells. We obtained a calibration factor for each antigen separately and used them to convert FMIA U/mL and EIA units into BAU/mL.

MNT of laboratory 1. The MNT of laboratory 1 was performed at the Finnish Institute for Health and Welfare (Helsinki, Finland), and the assay has been previously described in detail $(14,18)$. Briefly, the MNT of laboratory 1 was performed using Vero E6 cells and true duplicates of sera diluted serially from 1:4. After 4 days the cells were fixed with $30 \%$ formaldehyde, and the cytopathic effect (CPE) was measured. The viral strains used were hCoV-19/Finland/1/2020 (FIN-1) (GISAID accession ID EPI_ISL_407079) and hCoV-19/ Finland/FIN-25/2020 (FIN-25) (GISAID accession ID EPI_ISL_412971) in the analysis of positive- and negativeserum panels and FIN-1 in analyses of sera used in comparison to MNT of laboratory 2. A sample was considered positive when the NAb titer was $\geq 6$ for at least one virus and negative when titers for both viruses were $<4$. A sample was considered borderline if its highest titer was 4 . Negative samples were given a titer value of 2 for statistical analyses. In cases where the titers of the two viruses differed, the titer of the sample was defined as the highest of the two.

MNT of laboratory 2. The MNT of laboratory 2 was performed at the University of Turku (Turku, Finland), and the method has been previously described (16). The MNTs between laboratories 1 and 2 differed in viral isolate used, serum dilution, cell line, incubation time, and cell fixation. The MNT of laboratory 2 used VeroE6-TMPRSS2-H10 cells fixed with 4\% formaldehyde, and the CPE was measured after 3 days. The starting dilution for sera was 1:20 with 50 TCID $_{50}$ of SARS-CoV-2 variant FIN-25 (GISAID accession ID EPI_ISL_412971, GenBank accession no. MW717675), and neutralization titers were analyzed in duplicate. The NAb titer was defined as the last dilution resulting in $50 \%$ inhibition of cell death. The threshold for positivity was $\geq 20$. Negative samples were given a titer value of 10 for statistical analyses. FIN-1 represents lineage B (D614G substitution), and FIN-25 represents lineage B.1 with three amino acid substitutions (D614G, 41\% R682W, 45\% YQTQT 674 to 678 [16]) in the spike glycoprotein compared to the Wuhan-Hu-1 strain.

Comparison of FMIA, EIA, and MNT assays. We calculated the Spearman correlation coefficient $(\rho)$ and the statistical significance of the correlation between FMIA and EIA antibody concentrations and the two laboratories' NAb titers. In addition, we compared FMIA and EIA in their ability to detect antibodies induced by natural infection and vaccination. Samples that were borderline in MNT of laboratory 1 were considered positive. 
Ethical statement. The investigations were carried out under the General Data Protection Regulation (Regulation [EU] 2016/679, directive 95/46/EC) and the Finnish Personal Data Act (Finlex 523/ 1999). The study protocols for the collection of pre-COVID-19 pandemic samples and COVID-19 patient samples were approved by the Helsinki-Uusimaa health district ethical permissions 433/13/03/00/15 and HUS/1238/2020. The Finnish law on communicable diseases and the duties of the Finnish Institute for Health and Welfare $(30,31)$ allowed the implementation of the initial household transmission study without seeking further institutional ethical review. The vaccinee cohort $(n=20)$ was randomly selected from a larger cohort $(n=180)$ of vaccinated health care personnel of Turku University Hospital (16) approved by the Southwest Finland health district ethical permission ETMK 19/1801/2020. Written informed consent was obtained from all volunteers.

Data availability. The data and code are available from the corresponding author upon reasonable request.

\section{SUPPLEMENTAL MATERIAL}

Supplemental material is available online only.

SUPPLEMENTAL FILE 1, PDF file, 0.3 MB.

\section{ACKNOWLEDGMENTS}

We thank Leena Saarinen, Marja Suorsa, Lotta Hagberg, Esa Ruokokoski, Tuomo Nieminen, Hanna Valtonen, Katja Lind, Heidi Hemmilä, Tiina Pulliainen, Marja-Liisa Ollonen, Minna Haanpää, Katri Keino, Riitta Santanen, Christel Pussinen, Mervi Nosa, Anne-Mari Pieniniemi, and Anne Suominen.

N.E., C.V., and M.M. are coinvestigators in an unrelated study, for which THL has received research funding from GlaxoSmithKline Vaccines. A.S., A.H., A.K., S.M., J.L., P.J., L.K., T.D., and I.J. report no conflicts of interest.

The study was supported by funds from the Finnish Institute for Health and Welfare, University of Turku, and the Academy of Finland (grant numbers 336439, 336431, 337527, 335527, and 335530), the Finnish Medical Foundation, the Finnish governmental subsidy for health science research, and the Jane and Aatos Erkko Foundation (grant number 5360-cc2fc).

C.V., A.H., A.S., P.J., and L.K. performed the laboratory analyses. A.K., S.M., and T.D. recruited the volunteers and managed serum sample collection. A.S. and C.V. developed and optimized the assay. A.S., N.E., C.V., and M.M. analyzed the results. A.S., J.L., I.J., and M.M. designed the study and A.S., N.E., A.H., C.V., and M.M. drafted the manuscript. All authors approved the final version.

\section{REFERENCES}

1. WHO coronavirus (COVID-19) dashboard. 2020. World Health Organization. https://covid19.who.int. Accessed 4 August 2021.

2. Byambasuren O, Dobler CC, Bell K, Rojas DP, Clark J, McLaws M-L, Glasziou P. 2021. Comparison of seroprevalence of SARS-CoV-2 infections with cumulative and imputed COVID-19 cases: systematic review. PLoS One 16: e0248946. https://doi.org/10.1371/journal.pone.0248946.

3. Kalish H, Klumpp-Thomas C, Hunsberger S, Baus HA, Fay MP, Siripong N, Wang J, Hicks J, Mehalko J, Travers J, Pauly K, Spathies J, Ngo T, Adusei KM, Karkanitsa M, Croker JA, Li Y, Graubard BI, Czajkowski L, Belliveau O, Chairez C, Snead KR, Frank P, Shunmugavel A, Han A, Giurgea LT, Rosas LA, Bean R, Athota R, Cervantes-Medina A, Gouzoulis M, Heffelfinger B, Valenti $S$, Caldararo R, Kolberg MM, Kelly A, Simon R, Shafiq S, Wall V, Reed S, Ford EW, Lokwani R, Denson J-P, Messing S, Michael SG, Gillette W, Kimberly RP, Reis SE. 2021. Undiagnosed SARS-CoV-2 seropositivity during the first 6 months of the COVID-19 pandemic in the United States. Sci Transl Med 13:eabh3826. https://doi.org/10.1126/scitranslmed.abh3826.

4. Hellewell J, Russell TW, Beale R, Kelly G, Houlihan C, Nastouli E, Kucharski AJ, CMMID COVID-19 Working Group. 2021. Estimating the effectiveness of routine asymptomatic PCR testing at different frequencies for the detection of SARS-CoV-2 infections. BMC Med 19:106. https://doi.org/10 .1186/s12916-021-01982-x.

5. Huo X, Chen J, Ruan S. 2021. Estimating asymptomatic, undetected and total cases for the COVID-19 outbreak in Wuhan: a mathematical modeling study. BMC Infect Dis 21:476. https://doi.org/10.1186/s12879-021-06078-8.

6. McElfish PA, Purvis R, James LP, Willis DE, Andersen JA. 2021. Perceived barriers to COVID-19 testing. IJERPH 18:2278. https://doi.org/10.3390/ ijerph 18052278 .
7. Nasrallah GK, Dargham SR, Shurrab F, Al-Sadeq DW, Al-Jighefee $H_{\text {, }}$ Chemaitelly H, Al Kanaani Z, Al Khal A, Al Kuwari E, Coyle P, Jeremijenko A, Kaleeckal AH, Latif AN, Shaik RM, Rahim HFA, Yassine HM, Al Kuwari MG, Qotba H, Al Romaihi HE, Tang P, Bertollini R, Al-Thani MH, Althani AA, AbuRaddad LJ. 2021. Analytic comparison between three high-throughput commercial SARS-CoV-2 antibody assays reveals minor discrepancies in a highincidence population. Sci Rep 11:11837. https://doi.org/10.1038/s41598-021 $-91235-x$.

8. Nilsson AC, Holm DK, Justesen US, Gorm-Jensen T, Andersen NS, Øvrehus A, Johansen IS, Michelsen J, Sprogøe U, Lillevang ST. 2021. Comparison of six commercially available SARS-CoV-2 antibody assays: choice of assay depends on intended use. Int J Infect Dis 103:381-388. https://doi.org/10 .1016/j.ijid.2020.12.017.

9. Whitman JD, Hiatt J, Mowery CT, Shy BR, Yu R, Yamamoto TN, Rathore U, Goldgof GM, Whitty C, Woo JM, Gallman AE, Miller TE, Levine AG, Nguyen DN, Bapat SP, Balcerek J, Bylsma SA, Lyons AM, Li S, Wong AW-Y, GillisBuck EM, Steinhart ZB, Lee $Y$, Apathy R, Lipke MJ, Smith JA, Zheng T, Boothby IC, Isaza E, Chan J, Acenas DD, Lee J, Macrae TA, Kyaw TS, Wu D, $\mathrm{Ng}$ DL, Gu W, York VA, Eskandarian HA, Callaway PC, Warrier L, Moreno ME, Levan J, Torres L, Farrington LA, Loudermilk RP, Koshal K, Zorn KC, Garcia-Beltran WF, Yang D, et al. 2020. Evaluation of SARS-CoV-2 serology assays reveals a range of test performance. Nat Biotechnol 38:1174-1183. https://doi.org/10.1038/s41587-020-0659-0.

10. Iyer AS, Jones FK, Nodoushani A, Kelly M, Becker M, Slater D, Mills R, Teng E, Kamruzzaman M, Garcia-Beltran WF, Yang D, Miller TE, Oliver E, Fischinger F, Atyeo C, lafrate J, Calderwood SB, Lauer SA, Yu J, Li Z, Feldman J, Hauser BM, Caradonna TM, Branda JA, Turbett SE, LaRocque 
RC, Mellon G, Barouch DH, Schmidt AG, Schmidt AS, Alter G, Ryan ET, Harris JB, Charles RC. 2020. Persistence and decay of human antibody responses to the receptor binding domain of SARS-CoV-2 spike protein in COVID-19 patients. Sci Immunol 5:eabe0367. https://doi.org/10.1126/ sciimmunol.abe0367.

11. Favresse J, Eucher C, Elsen M, Gillot C, Van Eeckhoudt S, Dogné J-M, Douxfils J. 2021. Persistence of anti-SARS-CoV-2 antibodies depends on the analytical kit: a report for up to 10 months after infection. Microorganisms 9:556. https://doi.org/10.3390/microorganisms9030556.

12. Jääskeläinen $A J$, Kuivanen $S$, Kekäläinen $E$, Ahava $M J$, Loginov R, KallioKokko H, Vapalahti O, Jarva H, Kurkela S, Lappalainen M. 2020. Performance of six SARS-CoV-2 immunoassays in comparison with microneutralisation. J Clin Virol 129:104512. https://doi.org/10.1016/j.jcv.2020.104512.

13. Trivedi SU, Miao C, Sanchez JE, Caidi H, Tamin A, Haynes L, Thornburg NJ. 2019. Development and evaluation of a multiplexed immunoassay for simultaneous detection of serum IgG antibodies to six human coronaviruses. Sci Rep 9:1390. https://doi.org/10.1038/s41598-018-37747-5.

14. Ekström N, Virta C, Haveri A, Dub T, Hagberg L, Solastie A, Österlund P, Vihervaara T, Erlund I, Nohynek H, Melin M. 2021. Analytical and clinical evaluation of antibody tests for SARS-CoV-2 serosurveillance studies used in Finland in 2020. medRxiv. https://doi.org/10.1101/2021.01.21.21250207.

15. Jalkanen $P$, Pasternack $A$, Maljanen $S$, Melén $K$, Kolehmainen $P$, Huttunen M, Lundberg R, Tripathi L, Khan H, Ritvos MA, Naves R, Haveri A, Österlund $P$, Kuivanen $S$, Jääskeläinen $A J$, Kurkela $S$, Lappalainen $M$, Rantasärkkä K, Vuorinen T, Hytönen J, Waris M, Tauriainen S, Ritvos O, Kakkola L, Julkunen I. 2021. A combination of $N$ and $S$ antigens with $\lg A$ and IgG measurement strengthens the accuracy of SARS-CoV-2 serodiagnostics. J Infect Dis 224:218-228. https://doi.org/10.1093/infdis/jiab222.

16. Jalkanen $P$, Kolehmainen $P$, Häkkinen $H K$, Huttunen $M$, Tähtinen $P A$, Lundberg R, Maljanen S, Reinholm A, Tauriainen S, Pakkanen SH, Levonen I, Nousiainen A, Miller T, Välimaa H, Ivaska L, Pasternack A, Naves R, Ritvos O, Österlund P, Kuivanen S, Smura T, Hepojoki J, Vapalahti O, Lempainen J, Kakkola L, Kantele A, Julkunen I. 2021. COVID-19 mRNA vaccine induced antibody responses against three SARS-CoV-2 variants. Nat Commun 12: 3991. https://doi.org/10.1038/s41467-021-24285-4.

17. Mattiuzzo G, Bentley EM, Hassall M, Routley M, Richardson S, Bernasconi V, Kristiansen P, Harvala H, Roberts D, Semple MG, Turtle LCW, Openshaw PJM, Baillie K, Nissen-Meyer LSH, Brantsæter AB, Baxendale H, Atkinson E, Rigsby P, Padley D, Almond N, Rose NJ, Page M. 2020. Establishment of the WHO international standard and reference panel for anti-SARS-CoV-2 antibody. WHO/ BS/20202402. https://www.who.int/publications/m/item/WHO-BS-2020.2403.

18. Haveri A, Smura T, Kuivanen S, Österlund $P$, Hepojoki J, Ikonen N, Pitkäpaasi M, Blomqvist S, Rönkkö E, Kantele A, Strandin T, Kallio-Kokko H, Mannonen L, Lappalainen M, Broas M, Jiang M, Siira L, Salminen M, Puumalainen T, Sane J, Melin M, Vapalahti O, Savolainen-Kopra C. 2020. Serological and molecular findings during SARS-CoV-2 infection: the first case study in Finland, January to February 2020. Eurosurveillance 25:2000266. https://doi.org/10.2807/1560 -7917.ES.2020.25.11.2000266.

19. Lobo ED, Hansen RJ, Balthasar JP. 2004. Antibody pharmacokinetics and pharmacodynamics. J Pharm Sci 93:2645-2668. https://doi.org/10.1002/jps 20178 .

20. Chen X, Pan Z, Yue S, Yu F, Zhang J, Yang Y, Li R, Liu B, Yang X, Gao L, Li Z, Lin Y, Huang Q, Xu L, Tang J, Hu L, Zhao J, Liu P, Zhang G, Chen Y, Deng K,
Ye L. 2020. Disease severity dictates SARS-CoV-2-specific neutralizing antibody responses in COVID-19. Signal Transduct Target Ther 5:180. https://doi.org/10.1038/s41392-020-00301-9.

21. Long Q-X, Tang X-J, Shi Q-L, Li Q, Deng H-J, Yuan J, Hu J-L, Xu W, Zhang Y, LV F-J, Su K, Zhang F, Gong J, Wu B, Liu X-M, Li J-J, Qiu J-F, Chen J, Huang A-L. 2020. Clinical and immunological assessment of asymptomatic SARS-CoV-2 infections. Nat Med 26:1200-1204. https://doi.org/10.1038/s41591-020-0965-6.

22. Röltgen $K$, Powell AE, Wirz OF, Stevens BA, Hogan CA, Najeeb J, Hunter M, Wang $\mathrm{H}$, Sahoo MK, Huang $\mathrm{CH}$, Yamamoto $\mathrm{F}$, Manohar M, Manalac J, Otrelo-Cardoso AR, Pham TD, Rustagi A, Rogers AJ, Shah NH, Blish CA, Cochran JR, Jardetzky TS, Zehnder JL, Wang TT, Narasimhan B, Gombar S, Tibshirani R, Nadeau KC, Kim PS, Pinsky BA, Boyd SD. 2020. Defining the features and duration of antibody responses to SARS-CoV-2 infection associated with disease severity and outcome. Sci Immunol 5:eabe0240. https://doi.org/10.1126/sciimmunol.abe0240.

23. Choe PG, Kim K-H, Kang CK, Suh HJ, Kang EK, Lee S, Kim NJ, Yi J, Park WB, Oh M-D. 2021. Antibody responses 8 months after asymptomatic or mild SARS-CoV-2 infection. Emerg Infect Dis 27:928-931. https://doi.org/10 .3201/eid2703.204543.

24. Haveri A, Ekström N, Solastie A, Virta C, Österlund P, Isosaari E, Nohynek $\mathrm{H}$, Palmu AA, Melin M. 2021. Persistence of neutralizing antibodies a year after SARS-CoV-2 infection in humans. Eur J Immunol. https://doi.org/10 .1002/eji.202149535.

25. Glück V, Grobecker S, Tydykov L, Salzberger B, Glück T, Weidlich T, Bertok M, Gottwald C, Wenzel JJ, Gessner A, Schmidt B, Peterhoff D. 2021. SARSCoV-2-directed antibodies persist for more than six months in a cohort with mild to moderate COVID-19. Infection 49:739-746. https://doi.org/ 10.1007/s15010-021-01598-6.

26. Yao L, Wang G-L, Shen Y, Wang Z-Y, Zhan B-D, Duan L-J, Lu B, Shi C, Gao Y-M, Peng H-H, Wang G-Q, Wang D-M, Jiang M-D, Cao G-P, Ma M-J. 2021. Persistence of antibody and cellular immune responses in coronavirus disease 2019 patients over nine months after infection. J Infect Dis 224: 586-594. https://doi.org/10.1093/infdis/jiab255.

27. Fenwick C, Croxatto A, Coste AT, Pojer F, André C, Pellaton C, Farina A, Campos J, Hacker D, Lau K, Bosch B-J, Gonseth Nussle S, Bochud M, D'Acremont V, Trono D, Greub G, Pantaleo G. 2021. Changes in SARSCoV-2 Spike versus nucleoprotein antibody responses impact the estimates of infections in population-based seroprevalence studies. J Virol 95:e01828-20. https://doi.org/10.1128/JVI.01828-20.

28. Kristiansen PA, Page M, Bernasconi V, Mattiuzzo G, Dull P, Makar K, Plotkin S, Knezevic I. 2021. WHO international standard for anti-SARSCoV-2 immunoglobulin. Lancet 397:1347-1348. https://doi.org/10.1016/ S0140-6736(21)00527-4.

29. Dub T, Nohynek H, Hagberg L, Liedes O, Virta C, Solastie A, Vara S, Ekström $N$, Österlund $P$, Lind $K$, Valtonen $H$, Hemmilä $H$, Ikonen $N$, Lukkarinen T, Palmu AA, Melin M. 2021. High secondary attack rate and persistence of SARS-CoV-2 antibodies in household transmission study participants, Finland 2020. medRxiv. https://doi.org/10.1101/2021.07.25 .21260925.

30. Act on the National Institute for Health and Welfare (668/2008). 2008. www .finlex.fi/en/laki/kaannokset/2008/en20080668.pdf. Accessed 12 July 2021.

31. Communicable Diseases Act (1227/2016). 2016. www.finlex.fi/en/laki/ kaannokset/2016/en20161227.pdf. Accessed 12 July 2021. 